Impediments to Contract Enforcement in Day Labour Markets: A Perspective from India

Karthikeya Naraparaju

Indira Gandhi Institute of Development Research, Mumbai December 2014 http://www.igidr.ac.in/pdf/publication/WP-2014-050.pdf 


\title{
Impediments to Contract Enforcement in Day Labour Markets: A Perspective from India
}

\author{
Karthikeya Naraparaju \\ Indira Gandhi Institute of Development Research (IGIDR) \\ General Arun Kumar Vaidya Marg \\ Goregaon (E), Mumbai- 400065, INDIA \\ Email(corresponding author): karthikeya@igidr.ac.in
}

\begin{abstract}
In developing countries, lack of formal contract enforcement mechanisms is compensated by informal or relational governance enforced through trust, kinship, reputation, etc. This paper focuses on one such setting in India's urban informal economy: the 'day labour' market for casual labour. We survey seven such markets in Navi Mumbai (a city on the outskirts of Mumbai), and find considerable incidence of contract enforcement problems in the form of employers reneging on wage payments to labourers. We find that payments to labourers with access to social networks and a record of work done are less likely to be reneged. Further, consistent with the literature on the limits of relation-based contract enforcement, we find that labourers in large markets, with greater linguistic and caste-based diversity, are more likely to be reneged. We argue that interventions aimed at facilitating access to formal mechanisms might help overcome some of the limitations with relation-based enforcement.
\end{abstract}

Keywords: Urban informal economy; Day labour markets; Migrants; Contract enforcement;

JEL Code: O17, J49, R23, L14

\section{Acknowledgements:}

I would like to thank Dr. S. Chandrasekhar, Dr. Sripad Motiram, and Dr. Sudha Narayanan for their guidance and support. Support during the survey from Gopal Dubey (formerly with YUVA) and the rest of the team at YUVA is gratefully acknowledged. For helpful discussions and comments I would like to thank Prof. E. Somanathan, Prof. Geoffrey Hodgson, Upasak Das, Sumit Mishra, Ajay Sharma, and participants at the INET-YSI workshop at Antalya, Turkey and at the Centenary Research Scholars Workshop, University of Calcutta. I am alone responsible for any remaining errors. This paper is written as part of the "Strengthen and Harmonize Research and Action on Migration in the Indian Context" SHRAMIC, an initiative by Sir Dorabji Tata Trust and Allied Trusts (SDTT \&AT) 


\title{
Impediments to Contract Enforcement in Day Labour Markets:
}

\section{A Perspective from India*}

\author{
Karthikeya Naraparaju ${ }^{* *}$
}

\begin{abstract}
In developing countries, lack of formal contract enforcement mechanisms is compensated by informal or relational governance enforced through trust, kinship, reputation, etc. This paper focuses on one such setting in India's urban informal economy: the 'day labour' market for casual labour. We survey seven such markets in Navi Mumbai (a city on the outskirts of Mumbai), and find considerable incidence of contract enforcement problems in the form of employers reneging on wage payments to labourers. We find that payments to labourers with access to social networks and a record of work done are less likely to be reneged. Further, consistent with the literature on the limits of relation-based contract enforcement, we find that labourers in large markets, with greater linguistic and caste-based diversity, are more likely to be reneged. We argue that interventions aimed at facilitating access to formal mechanisms might help overcome some of the limitations with relation-based enforcement.
\end{abstract}

Keywords: Urban informal economy; Day labour markets; Migrants; Contract enforcement; JEL Codes: O17, J49, R23, L14

\footnotetext{
"Acknowledgements: I would like to thank Dr. S. Chandrasekhar, Dr. Sripad Motiram, and Dr. Sudha Narayanan for their guidance and support. Support during the survey from Gopal Dubey (formerly with YUVA) and the rest of the team at YUVA is gratefully acknowledged. For helpful discussions and comments I would like to thank Prof. E. Somanathan, Prof. Geoffrey Hodgson, Upasak Das, Sumit Mishra, Ajay Sharma, and participants at the INET-YSI workshop at Antalya, Turkey and at the Centenary Research Scholars Workshop, University of Calcutta. I am alone responsible for any remaining errors. This paper is written as part of the "Strengthen and Harmonize Research and Action on Migration in the Indian Context" SHRAMIC, an initiative by Sir Dorabji Tata Trust and Allied Trusts (SDTT \&AT).

${ }^{* *}$ Doctoral Candidate. Indira Gandhi Institute of Development Research (IGIDR), Gen. A.K. Vaidya Marg, Goregaon (E), Mumbai. India - 400065. E-mail: karthikeya@igidr.ac.in
} 


\section{INTRODUCTION}

While it is acknowledged that exchange through markets is beneficial to the contracting parties, there arise situations where certain unilateral actions of one party increase its own payoff while simultaneously harming the interests of the other party. Reneging on payment obligations after the good is delivered is one of such actions, which have been collectively termed as 'opportunism' in the literature (Williamson 1985). Since such behaviour is detrimental to the functioning of markets, contract enforcement mechanisms are instituted to penalize the erring agents. While enforcement through formal mechanisms such as a court of law is more popular, wherever the state is 'absent, corrupt, or too slow to be usable', and the transaction costs of using it are very high, alternative modes known as "informal" or "relational" enforcement mechanisms, emerge to provide the necessary economic governance (Dixit 2004).

In this paper, we look at enforceability of contracts - specifically, oral job contracts between employers and labourers - in a particular setting of India's urban informal economy where formal enforcement mechanisms are virtually absent, viz. the market for daily wage casual labour engaged in construction and related activities in the city of Navi Mumbai. In the absence of a formal mechanism, we explore the feasibility and effectiveness of informal enforcement mechanisms in these markets.

As is the case of several urban areas, especially in developing countries, Navi Mumbai is characterised by the presence of day labour markets at various locations in the city. These markets involve labourers seeking daily wage employment from their prospective employers, known as labour contractors. The street corners where these markets are held each morning are known as 'nakas', which is the word used to denote a road junction in Marathi, 
the local language ${ }^{1}$. We survey seven such nakas and find considerable incidence of contract enforcement problems in the form of employers reneging on wage payments to the labourers. In the absence of a written job contract, labourers are unable to invoke formal enforcement mechanisms in these markets. In this context, we intend to understand the factors associated with wage reneging using the framework of informal enforcement mechanisms.

The literature on informal or relational contract enforcement is extensive and includes both theoretical (e.g. Dixit 2003, 2004) as well as empirical work, motivated by the study of markets in historical settings (e.g. Greif 1993; Milgrom et al. 1990) as well as those in least developed and transition countries (e.g., Fafchamps 1996, 2004; McMillan and Woodruff 1999).

Borrowing from the insights in this literature, we test for several of its predictions in our setting. In particular, we look for evidence on information transmission among the labourers about opportunistic employers, the limits to such transmission in large and diverse markets, and the deterrence effect of certain factors in reducing the incidence of reneging.

The markets we examine are predominantly composed of migrant labour, including those from within the state of Maharashtra (where Navi Mumbai is located) as well as from other states. In all, our sample of about 400 labourers includes migrants from fifteen different states of India. Using variation in the size and diversity (in terms of workers' native language and caste) in the composition of the nakas, we find that payments to labourers belonging to larger and more diverse markets are more likely to be reneged, confirming the theoretical predictions of Dixit (2003). We also find that greater the share of native speakers of the local language (Marathi) ${ }^{2}$ at a naka, lower is the incidence of wage reneging. We interpret this finding in the light of considerable political antagonism against non-Marathi migrant labour in and around the city of Mumbai. Further, among the non-Marathi migrants, those who came

\footnotetext{
${ }^{1}$ For this reason, we shall use the terms 'markets' and 'nakas' interchangeably.

${ }^{2}$ We classify the labourers' native language on the basis of the language spoken in their native districts.
} 
to these markets through social networks are found to be less vulnerable than those who did not. We also find that payments to labourers who maintain a record of work done are less likely to be reneged.

Although we focus on a specific setting, we believe that our findings have some broader relevance. Estimates suggest that in 2011-12, 72 percent of all urban workers and 96 percent of those working in the construction sector in urban areas do not have a written job contract, ${ }^{3}$ undermining their ability to invoke formal enforcement mechanisms in case of any disputes.

In this context, our study can be seen as a micro-empirical exercise to gain insights into the mechanisms of the important, although relatively underexplored, area of relation based contract enforcement in India's urban informal economy. Further it also complements empirical literature on informal contract enforcement from India (Jain and Sood 2012) as well as from other countries (such as Fafchamps (1996, 2004) on Sub-Saharan Africa; and McMillan and Woodruff (1999) on Vietnam).

The rest of the paper is organised as follows: in section 2, we discuss the conceptual framework that is drawn from the literature and the testable hypotheses that emerge from this; section 3 provides details of the day labour markets in Navi Mumbai, our sampling strategy, and various sample level characteristics relevant for our study; in section 4 , we provide the empirical results; and section 5 concludes.

\footnotetext{
3 Source: National Sample Survey on Employment and Unemployment Situation in India, 2011-12. The classification of workers' employment type is according to the 'Usual Principal Status'.
} 


\section{CONCEPTUAL FRAMEWORK}

In this section, we will summarize the essential details of the relevant literature that provide us with a set of testable hypotheses for the empirical analysis. This framework is broadly drawn from Fafchamps (1996) and Dixit (2004), while adapting it to our setting.

Literature suggests that there are broadly three types of mechanisms through which contracts are honoured: those based on the guilt consciousness of the contracting parties; those based on coercion; and those based on repeated interaction. Among these, guilt or honesty is internal to an individual and its degree may vary across individuals (Platteau 1994a, 1994b). Coercion can be drawn from two sources: legitimate and illegitimate. The state has a monopoly over legitimate coercion, enforced through formal mechanisms such as courts. Illegitimate coercion involves private parties resorting to threats and even violence to enforce contracts. Typically, this involves the aggrieved party paying a third party to coerce the erring partner into honouring the contract $^{4}$ and is therefore considered to be costly.

The mechanism of repeated interaction operates through the principle of quid-proquo: the threat of termination of the relationship in case of a breach, forces the contracting parties to honour their commitments. For this mechanism to work, the relationship should be worth preserving in the first place. If there are lucrative outside options for the agents, then termination of the relationship is not a credible threat to deter opportunism. If severing the bilateral relationship is not enough, punishments could also be imposed at the level of a group within which the agents trade frequently. However, for these group (or multilateral) punishments to work, there should be a mechanism through which the agents share information about those who renege on their contracts. Enforcement in these settings works through agents' ties along informal institutions such as kinship, ethnicity, etc. For this reason,

\footnotetext{
${ }^{4}$ See Gambetta (1993) for a discussion on Sicilian Mafia's role in enforcing contracts (as discussed in Dixit, 2004).
} 
cohesion and stability in the composition of the group is seen to be important (see Chapter 3 , Dixit (2004) for a survey of the relevant literature).

To fix these ideas into our context, let us assume that there are various types, of employers in the market, denoted by $\tau$, and distributed along a continuum from $\underline{\tau}$ (the worst type) to $\bar{\tau}$ (the best type) i.e. $\tau \in[\underline{\tau}, \bar{\tau}]$. The 'best types' are defined as those that honour the contract regardless of the enforcement mechanism, while the 'worst types' always renege on their obligations. Reflecting the asymmetric nature of information in these markets, we assume that while each employer knows his own type, the labourer does not know, ex-ante, the type of the employer he is working for.

The contract enforcement mechanisms discussed above can then be denoted as the following:

$G(\tau)$ - denotes the disutility to the employer from reneging on the contract that is caused because of his guilt consciousness or honesty. Since the best types are, by definition, more honest, $\mathrm{G}(\tau)$ is increasing in $\tau$.

$P(\tau, \mathrm{C}, \mathrm{i})$ - denotes the cost of contract breach to the employer from various forms of coercion - legitimate action such as court proceedings, penalties by the state, etc., or illegitimate coercion in the form of threats, harassment, etc. Effectiveness of coercion increases if the labourer has a written contract or a record of work done (C). Moreover, identity of the worker (i) with whom the transaction is done also matters - if a worker lacks the capacity to invoke either legitimate or illegitimate coercive mechanisms, it is easier to renege on payments to him.

The repeated interaction mechanism is captured by the following terms: $\operatorname{EV}(\tau, \mathrm{M}, \mathrm{i})$ - This denotes the incremental value an employer attaches to his relationship with a particular labourer (i). In the event of a contract breach, leading to the termination of the relationship, this term denotes the employer's expected discounted value of future 
transactions with the labourer. The more skilled a labourer the more valuable his services are to an employer. This term also depends on certain market characteristics (M) such as the size of the market: larger the number of labourers of a particular type, larger is the set of alternatives to the employer to choose from and hence lower is the value he attaches to his relationship with a particular labourer.

$\operatorname{EW}(\tau, \mathrm{M}, \mathrm{i})-$ This denotes the loss of reputation in the market for the reneging employer and the consequent inability to transact there in the future. It is defined as the discounted value of the employer's future transactions in the market. This cost depends crucially on the extent to which information about a contract breach is transmitted across the market. Literature suggests that information sharing works better in small groups that are connected by 'family relationships, neighbourhood structures, and ethno-linguistic ties, because such links facilitate repeated interactions and good communication' (Dixit 2004). Moreover, smaller groups have been shown to perform better in reducing collective-action dilemmas in enforcing punishments (Ostrom 1990). In a theoretical model, Dixit (2003) shows that as the distance between the agents - either in the geographic or in the socio-economic space - increases, the scope for information sharing about the erring agents reduces. Thus the effectiveness of the reputation mechanism (and hence of relation-based governance) depends on market characteristics (M) such as its size, diversity in the composition of workers, etc. ${ }^{5}$

From the labourers' perspective, prior information about the employers' credibility (say $\Omega$ ) would help them in choosing job offers that are trustworthy. This information could either be obtained from the labourer's social networks at the market or it could be accumulated through his own experience of observing various employers over the years. However, as we will see in the next section, these markets are characterised by irregular employment, with the labourers finding employment only for about 15 days a month, on the

\footnotetext{
${ }^{5}$ Since each of these costs will be incurred only if the contract is reneged, $P, E V$, and $E W$ also depend on the type of the employer, $\tau$.
} 
average. Given this vulnerability, while prior information about an employer might improve the outcomes for the labourers, it is not a precondition for their participation in the market.

This set up gives us certain testable hypotheses. We summarize these below:

(a) If a labourer does not have the capacity to coerce, either through legitimate means such as political support, a written contract, or through illegal means such as violence and threats, then this reduces the term $\mathrm{P}(\tau, \mathrm{C}, \mathrm{i})$ for his employer and increases the chances of reneging on wage payments. Hence, ceteris paribus, the more vulnerable a worker, the more likely it is that his payments are reneged.

(b) Since labourers belonging to larger, more diverse markets are less likely to meet and interact with each other, the risk of losing reputation for the opportunistic employer is lower in these markets, vis-a-vis smaller and more homogenous markets. Thus, ceteris paribus, the larger and more diverse the market, the lower is the term $\operatorname{EW}(\tau, \mathrm{i}, \mathrm{M})$ for the employers and higher the likelihood of a contract breach.

(c) The better information that a labourer has about the market and the employers $(\Omega)$, the lower is his likelihood of dealing with an opportunistic employer. Thus, ceteris paribus, labourers with access to social networks, and those with experience in the market, are less likely to experience a contract breach.

\section{MARKET AND DATA CHARACTERISTICS}

Labourers gathering for work at the nakas each morning are recruited mostly in construction and allied sectors. In recent times, the construction sector has been booming in India. ${ }^{6}$ With

\footnotetext{
${ }^{6}$ Between 1999-00 and 2009-10, employment in construction increased by about 26 million, the highest among any major sectors in the economy (Mehrotra et. al., 2012). Between 2000-01 and 2011-12, the GDP of the construction industry grew by 14.58 percent at constant prices on average (Reserve Bank of India, 2012).
} 
this, the day labour markets have become ubiquitous in various cities of the country. However, with the exception of a couple of studies such as Singh (2002) in the context of Delhi and Mukherjee et al. (2009) in the context of Mumbai, the street corner markets for casual labour have been relatively underexplored by researchers. ${ }^{7}$ Navi Mumbai, where our study is based, is a planned city on the outskirts of the city of Mumbai. With Mumbai being saturated for space, Navi Mumbai has been witnessing hectic residential and commercial construction activity over the past few years.

The naka workers are not attached to any particular contractor. They reside within the city, usually in the vicinity of the nakas. The employers in the construction industry outsource the hiring of naka workers to labour contractors. These contractors arrive in the market every morning and pick up the workers as per their requirements for the day. Thus, labour contractors act as an intermediary between the actual employers and the naka workers. In fact, the naka workers usually do not interact directly with the employers and they transact only with the labour contractors. These features have also been found in other studies of naka workers in Mumbai (Mukherjee et al. 2009).

(a) Survey and Sampling Strategy

The survey was conducted in collaboration with 'Youth for Unity and Voluntary Action (YUVA),' a Non-Governmental Organisation (NGO) based in Navi Mumbai, during January and February 2013. In addition to recording labour market outcomes of the naka workers such as wages, employment, occupational hazards etc., the survey also collected information on various aspects of the migrant workers' integration into the city such as housing, basic amenities, political representation, financial inclusion etc.

\footnotetext{
${ }^{7}$ Moreover, neither of these studies looks at the problem of reneging on wage payments in these markets.
} 
The city of Navi Mumbai is divided into fourteen administrative units called 'nodes'. We surveyed seven nakas spread across six nodes in the city. The markets we surveyed are: Belapur, Kharghar, Kohinoor, Nerul, Sanpada, Sukhapur, and Vashi. Although it is acknowledged that there is a significant presence of naka workers in Navi Mumbai, there are no reliable official statistics that provide an estimate of their extent and distribution across various parts of the city. YUVA estimates that about 4,000 workers assemble for employment at the seven nakas mentioned above. However, these labourers are not distributed equally across the various nakas, as some markets have a larger congregation of workers than others.

Since our objective is to target a population that is frequenting a specific type of market, a typical household survey would not achieve our purpose. Hence, we adopt intercept point sampling methods, also known as time-and-space sampling methods, ${ }^{8}$ wherein individuals from the target population 'are sampled during set time periods at locations where they are likely to congregate' (Jain and Sood, 2012). Accordingly, we visited these markets during the time of the day when workers congregate seeking work (i.e. between 8:00 A.M. and 10:00 A.M.) and surveyed a sample of 399 labourers which corresponds to about 10 percent of YUVA's estimates for naka workers in Navi Mumbai. ${ }^{9}$ The sample is distributed across the seven nakas in accordance with YUVA's estimates of the distribution of total workers. Thus, our sample has the highest representation from Kharghar (31 percent), followed by Nerul (17 percent), Sukapur (16 percent), Sanpada (12 percent), Kohinoor (10 percent), Belapur (8 percent), and Vashi (6 percent). The size of the sample at each naka is a

\footnotetext{
${ }^{8}$ See Kalton (2001) for a discussion of the method, and Jain and Sood (2012) for an application in India.

${ }^{9}$ This method of sampling introduces certain biases. For instance, we do not control the labourers' selection into migration or into the naka worker profession. Further, we only survey those workers who are available at the market during our enumeration exercise and might have missed out on some of the workers who did not turn up at the naka during the days we visited or were picked up for work before we could survey them. In spite of these limitations, given the structure of these markets, we believe that this is the appropriate survey methodology for our purpose.
} 
rough indicator of the magnitude of construction related activities that are underway in and around these areas.

\section{(b) Demographic Characteristics}

Being composed entirely of migrant labourers, our sample has representation from workers who have migrated from fifteen different states, including Maharashtra (which accounts for about 46 percent of the sample), Telangana (12 percent), Uttar Pradesh (11 percent), Karnataka (11 percent), Bihar (6 percent), Rajasthan (4 percent), West Bengal (3 percent), Odisha ( 2 percent), Madhya Pradesh ( 2 percent), and Others ( 3 percent). Since the native languages spoken in these states are different, our sample has native speakers of eight different languages.

The sample predominantly consists of male workers (representing about 93 percent) who are young, with the median age of the workers being 30 years (and mean of 33 years). About 90 percent of the sample is below the age of 45 years. The labourers first migrated for work about ten years ago, on an average ${ }^{10}$. They have been coming to these nakas for about eight years on an average, thus reflecting the long-term nature of their migration to Navi Mumbai.

Hindus constitute the majority (79 percent of the sample), followed by Muslims (10 percent), and Buddhists (9 percent). Among those who chose to reveal their social group (i.e. 94 percent of the sample), most of the workers belonged to the Scheduled Castes (SCs) (40 percent), followed by the Scheduled Tribes (STs) (25 percent), Other Backward Classes (OBCs) (21 percent), with the lowest representation from Others (14 percent). ${ }^{11}$ The migrants are not very well educated: about 40 percent of the sample is illiterate and among the literate about 80 percent have not matriculated. Also, majority of the migrants do not have any major

\footnotetext{
${ }^{10}$ We shall use the terms 'average' and 'mean' interchangeably.

${ }^{11}$ The SCs, STs, and OBCs have been traditionally discriminated in India's hierarchical caste structure.
} 
assets in their villages, with about 55 percent of them being landless while another 40 percent has land holdings of less than 2 hectares.

The nakas have some variation with respect to the distribution of workers belonging to various states. For instance while workers from Maharashtra have substantial representation across all the nakas, about 60 percent of migrants from Telangana and about 70 percent of migrants from Bihar are in the Kharghar naka. Thus, each naka is characterised by varying degrees of diversity in terms of the native languages, castes, and the states of origin for the workers. In order to gauge the extent of this diversity, we calculate the fractionalization index (Alesina et. al. 1999), defined as the following:

$$
\text { Fractionalization }=1-\sum_{i=1}^{n} s_{i}{ }^{2}
$$

Where $s_{i}$ denotes the share of migrants from state (or caste; or speaking a language) ' $i$ ' among all the workers in the naka. The index measures the probability that two randomly drawn people from a naka belong to different castes or states, or speak different languages (Alesina et. al 1999). Thus, higher values of the index indicate that there is greater diversity in the composition of the naka. We calculate the linguistic and caste based fractionalization for each naka and find that Kharghar has the greatest diversity while Kohinoor naka, which has 72 percent of its constituents from Maharashtra, has the lowest. In Table 1, we summarize various naka level characteristics.

\section{Insert Table 1 here}

\section{(c) Labour Market Characteristics}

(i) Employment and wages: As mentioned above, labourers in our sample are predominantly employed in construction and allied activities such as painting, plumbing, carpentry, etc. On average, workers get employment for about fourteen days in a month (median of 15 days), reflecting the irregular availability of work in these markets. There is no significant variation 
in the average working days across nakas with the exception of Belapur which has the lowest average at 11 days (and the lowest median at 10 days). Although these markets are located in the same city, there is not much mobility of workers across them with about 83 percent of the sample reporting that they do not visit other nakas. While distance between the nakas is reported to be a significant factor hindering the movement, workers also mentioned other factors such as lack of friends and acquaintances in other nakas.

Table 2 gives the average and median daily wages earned by workers belonging to various occupations. Since construction workers are themselves a heterogeneous group with different levels of skills among the workers, we classify them further into three groups: low wage, medium wage, and high wage workers. The average wages across these categories range from about Rs 270 to Rs 575. Painters are paid the next highest daily wage after highwage construction workers. Those classified as others include plumbers, carpenters, head load workers, etc. Although the workers are classified as daily wage labourers, their wages are usually paid at the end of their entire work assignment with the contractor, which, in some cases, might last up to a week or two.

\section{Insert Table 2 here}

(ii) Reneging on wage payments: As given in Table 3, there is a significant problem of contract enforcement in these markets with 154 labourers or about 39 percent of the sample reporting that their wage payments were reneged at least once since they started working in these markets. Moreover, 39 percent of those who experienced reneging have reported that this has occurred more than four times.

\section{Insert Table 3 here}

Broadly, reneging on wages could take two forms. The employer could make partial payment or he could completely deny payment. It can be argued that partial payment could also result from an inefficient job done by the labourer. Denying the payment altogether, 
however, can be seen as symptomatic of opportunism by the employers. Table 4 shows that the nature of reneging in these markets is predominantly in the form of avoiding the payment altogether (about 75 percent of those who experienced reneging).

\section{Insert Table 4 here}

Loss of wages as a result of reneging has cost the labourers considerably: Table 5 shows that about 38 percent of those who've experienced reneging have reported to have lost more than Rs. 10,000, a significant loss for a daily wage labourer with no other substantial assets to smoothen his consumption. However, in spite of the magnitude of the problem, we see from Table 6 that the labourers have not approached any formal mechanism to redress their grievances, with as many as 94 percent of the labourers reporting to have not done anything after their wage payments were reneged.

\section{Insert Tables 5 and 6 here}

Our conceptual framework in Section 2 can provide us with several insights into this problem. First, the nature of the day labour market is such that it consists of a large pool of migrant labourers, who come to these markets from various regions of the country. To the extent that the nature of the work is low or semi skilled, and does not require significant training for the labourer, the employer need not have to be dependent on a particular labourer to get his work done. In other words, the value that an employer attaches in maintaining his relationship with a particular labourer $(\operatorname{EV}(\tau, \mathrm{i}, \mathrm{M}))$ is low in these markets.

Second, as outlined in Section 2, one of the mechanisms through which enforcement can take place is through coercion (i.e. $\mathrm{P}(\tau, \mathrm{C}, \mathrm{i})$ ): both legitimate as well as illegitimate. Here it is worth noting that Mumbai has had a history of political antagonism towards migrant labour from outside Maharashtra. Politicians often resort to the rhetoric that locals are losing out on jobs opportunities to the migrants, which on some occasions have even led to attacks on migrants from the rest of India (see Times of India, 2008). Migrants in low-skilled 
occupations are especially vulnerable to this adverse political climate. Given this, for an employer, ceteris paribus, the cost of reneging on payments to migrants from outside Maharashtra is likely to be lower than the same for local (Marathi speaking) labourers.

In Table 7, we provide the incidence of reneging by the caste-group of the labourers for Marathis $^{12}$ and non-Marathis respectively. While the incidence of reneging for Marathi workers is considerable (35 percent), it is lower than the same for the non-Marathis (44 percent). Also, we see that except for the OBCs, incidence of reneging among Marathis is lower than that of non-Marathis for all the other caste groups, although the difference is marginal for the STs. Among Marathi OBCs, about 50 percent of those who experienced a contract breach have reported to have been paid partially, the highest proportion among all migrants. Although it is not clear if partial payment is a reflection of the quality of work done, higher incidence of reneging among Marathi OBCs (as compared to non-Marathi OBCs or other Marathi speaking labourers) needs to be seen in the light of this observation.

\section{Insert Table 7 here}

As noted by Fafchamps (1996), if the nature of the contract (i.e. ' $\mathrm{C}$ ' in $\mathrm{P}(\tau, \mathrm{C}, \mathrm{i})$ ) is such that even if no formal agreements are written, if there are documents that ease the burden of proof of work done, then it becomes easier to impose the coercion costs on the reneging employer. Thus, employers are less likely to renege on payments to labourers who have some proof of the work done. In our sample, about 11 percent of the labourers have reported to have maintained records of work done. Although these records might not always be legally enforceable, they might at least help the aggrieved labourers approach a private redressal mechanism such as an NGO, etc. Confirming the benefits of this record keeping, we see that incidence of reneging is lower among those who have a work record (30 percent) as compared to those who do not (40 percent).

\footnotetext{
${ }^{12}$ From our field experience, we found that migrants from districts of Bidar, Bijapur, and Gulbarga in Karnataka that share a border with Maharashtra, are also fluent speakers of Marathi. Hence we have included them as part of Marathi speaking migrants. These districts account for about 10 percent of our sample.
} 
We also noted in Section 2 that labourers with access to better information networks $(\Omega)$ are less likely to experience reneging on wage payments. In the survey, we asked the labourers how they came to know about these markets. About 62 percent of the sample has reported to have come to these markets through friends and relatives. We see that payments to labourers who came through social networks to these nakas are slightly less likely to be reneged than to those who came by themselves ( 37 percent versus 41 percent).

In addition, we intend to capture the effect of the distance over which the workers have migrated through a continuous variable of distance of native district from Mumbai. Exante, this could go either way: it could be argued that migrants who come from far-off places have weak community bonding at their destination in the initial phases of migration and hence are more vulnerable (see Mukherjee et al. 2009); on the other hand, long-distance migrants might choose to migrate to a place precisely because they have pre-existing networks.

We find that the benefits of access to social networks are more pronounced among workers who migrated from non-Marathi speaking districts, which are farther away from Mumbai. In particular, we see that Marathi-speaking migrants in our sample predominantly come from districts that are within a radius of about $550 \mathrm{Kms}$ from Mumbai: only 2 out of a total of 223 Marathi-speaking labourers come from districts that are farther than $550 \mathrm{Kms}$ from Mumbai. Similarly, out of the 176 non-Marathi speakers in the sample, only 5 come from districts that are less than $550 \mathrm{Kms}$ away from Mumbai.

Defining long-distance migrants as those whose native district from Mumbai is farther than $550 \mathrm{Kms}$, we see that while, on the whole, they have higher incidence of wage reneging (45 percent) than those who come from shorter distances (34 percent), among long-distance migrants, payments to those who came through social networks are less likely to be reneged (41 percent) than to those who did not (52 percent). Interestingly, for short-distance migrants 
(who are almost entirely composed of Marathi speakers), social networks do not seem to matter and they seem to be doing better than the long-distance migrants regardless of the presence of social networks. ${ }^{13}$

\section{Insert Table 8 here}

In the next section, we shall discuss the results of our econometric analysis. In addition to confirming whether the findings discussed in this section are statistically significant, we also test for the importance of market level characteristics such as its size, diversity, etc.

\section{EMPIRICAL RESULTS}

We consider the following explanatory variables for each of the mechanisms mentioned in Section 2:

Variables capturing the coercion mechanism $(\mathrm{P}(\tau, \mathrm{C}, \mathrm{i}))$ : The effectiveness of the 'coercion' component can be captured by whether the migrant is Marathi or not. However, since the difference in the incidence of reneging between Marathis and non-Marathis is not statistically significant for OBCs and STs, we do not make a distinction between the two for these social groups. For SCs and Others, we interact the dummy of being a Marathi worker with the caste status of the individual. Since the OBCs have the highest incidence of reneging, we take them as the base category. Thus, we have six categories - OBCs, STs, Marathi SCs, Non-Marathi SCs, Marathi Others, and non-Marathi Others. The deterrence effect of dealing with a Marathi worker is also captured at the level of the market by the share of Marathi speaking workers. It is expected that higher the share of Marathi speakers at a naka, lower is the likelihood of reneging.

\footnotetext{
${ }^{13}$ The cut-off of $550 \mathrm{Kms}$ is not sacrosanct and we have verified our results with farther distances and our inferences remain broadly similar.
} 
In addition, we incorporate a dummy for maintenance of record of work done to capture the coercive effect of documents that ease the burden of proof of work done (i.e. capturing ' $\mathrm{C}$ ' in $\mathrm{P}(\tau, \mathrm{C}, \mathrm{i}))$.

Variables capturing the risk of reputation loss for the employer $(\operatorname{EW}(\tau, \mathrm{i}, \mathrm{M}))$ : Since a large and diverse market reinforces anonymity among the labourers, limiting their capacity to share information about opportunistic employers, the efficacy of the reputation mechanism is weaker in such markets. We capture this effect by naka level characteristics such as size, linguistic fractionalization, and caste fractionalization.

Variables capturing the information set of the labourers $(\Omega)$ : As seen from Table 8, since the presence of social networks is seen to be effective among the long-distance migrants, we incorporate a dummy where the short-distance migrants are the base category, and the longdistance migrants are split into two categories: those who came through social networks, and the rest.

Further, as noted in Section 2, the more experienced a labourer is, the better informed he is likely to be of opportunistic employers. However, it is also plausible that longer the time a labourer spends in the market the more likely it is that he might have come across opportunistic employers at some point in time. Since our survey asked whether the labourers had ever experienced reneging, experience in these markets is likely to have two opposite effects on the incidence of wage reneging. We capture these in Figure 1, through a ' $U$ ' shaped pattern in the incidence of reneging with respect to the experience of workers. ${ }^{14}$ In the multivariate regression framework, we intend to capture this non-linearity by considering years spent working at the naka along with its square term. We also consider if the migrant has any previous experiencing of migrating and working elsewhere before coming to these nakas.

\footnotetext{
${ }^{14}$ Figure 1 captures the effect of experience on incidence of reneging through the local polynomial smoothing technique, along with 95 percent confidence interval. For details on the technique, see Fan and Gijbels (1996).
} 


\section{Insert Figure 1 here}

In addition, we have considered the type of work that the labourers are engaged in: three types of construction workers (low, medium, and high skilled), painters, and a residual category. We also incorporate other demographic characteristics such as caste, religion, and education.

In Tables 9 and 10, we provide the odds-ratio estimates for two sets of models of logistic regression predicting the incidence of reneging on wage payments in these markets. Each set has four different specifications capturing market level characteristics of size, linguistic fractionalization, caste fractionalisation, and share of Marathi-speaking workers, respectively. ${ }^{15}$ The models in Table 9 and Table 10 differ in the following way: in Table 9, we provide the estimates of the effect of social networks among long-distance migrants and do not differentiate between the Marathis and non-Marathis when considering the impact of caste. In Table 10, on the other hand, we differentiate between Marathis and non-Marathis within SCs and Others castes and do not have the social network and distance interaction dummy. ${ }^{16}$

We see from Tables $9 \& 10$ that while education and religion do not have a significant impact on the odds of facing a contract breach, when a distinction is not made between Marathis and non-Marathis (Table 9), we see that caste is not statistically significant, except for STs who have about 45 to 50 percent lower odds of facing a contract breach than the OBCs, however this effect is weak (and similarly for Others in Model 1). In Table 10, where we distinguish between Marathis and non-Marathis among SCs and Others, we see that the odds of contract breach for Marathi SCs are about 60 percent lower than the same for OBCs. Similarly, the odds of contract breach for Marathi Others are about 75 to 80 percent lower

\footnotetext{
${ }^{15}$ Since the odds-ratios of the fractionalization indices were found to be very large, we considered the standard normal variates of these indices.

${ }^{16}$ Since the distance and Marathi dummies share significant overlap in the sample, we cannot have both of them in the same specification.
} 
than the same for OBCs. For Non-Marathi SCs and Others, the odds of a contract breach are not statistically different from those facing OBCs. On the other hand, the odds of contract breach for STs (Marathis and non-Marathis combined) are about 50 to 55 percent lower than the same for OBCs.

We see that, ceteris paribus, the odds of experiencing a contract breach for those who have a record of work done are lower by about 50 to 60 percent (depending on the various specifications in Tables $9 \& 10$ ) than that of those who do not maintain a work record.

With respect to occupations, Painters seem to be particularly more vulnerable than others. Ceteris paribus, the odds of wage payments being reneged to a painter is about 100 to 120 percent higher than the same for a medium wage earning construction worker. Here it is worth noting that a substantial proportion (about 35 percent) of painters who experienced reneging have reported that they have received partial payments suggesting their employers might have had an issue with the quality of their work.

Looking at the impact of experience, we find that years spent at the naka has an odds ratio of less than one, whereas square of years spent has an odds ratio of greater than one, confirming the ' $U$ ' shaped pattern. We also see that long-distance migrants who came to these markets without any social networks are more vulnerable. In particular, ceteris paribus, the odds of wage payments being reneged to these workers are about 150 to 220 percent higher than the short-distance migrants. On the other hand, for long-distance migrants who come through social networks, the odds of facing a contract breach are not statistically different from the short-distance migrants.

With respect to market level characteristics, we see that, ceteris paribus, larger the size of the market, greater the odds of contract breach of the labourers. Similarly, higher the language and caste fractionalization indices, greater are the odds of experiencing wage 
reneging. Moreover, greater the share of Marathi speaking workers in a market, lower is the incidence of contract breach.

Thus we find that experienced workers as well as those with access to social networks and a record of work done are less vulnerable than others. Moreover we find that as the size and diversity of a market increase, it becomes difficult to sustain informal contract enforcement.

Some caveats regarding our study are in order. While our results seem to suggest that the labour contractors are strategically exploiting the anonymous nature of large and diverse markets, since we do not model employer behaviour in particular, we do not explicitly capture the precise mechanisms through which this might be taking place. In particular, we recognise that the evolution of large, diverse markets could be a complex, endogenous process and the cross-sectional nature of our study does not capture this adequately. However, despite these caveats, our results are broadly in conformity with the literature on the limits of relation-based contract enforcement.

\section{CONCLUSION}

In this paper, we have looked at contract enforcement mechanisms in the specific setting of India's urban informal sector - the day labour market for construction labour in Navi Mumbai. We find that formal mechanisms of enforcement are non-existent here. In their absence, workers face considerable risk of loss of their wages. Although the workers seem to be relying on informal mechanisms (such as social networks) to negotiate these markets, their effectiveness in large and diverse settings such as these is found to be limited. Our findings suggest that steps to enhance the bargaining power of the workers (such as promotion of maintenance of a record of work done) would help them in accessing the formal institutions of enforcement (such as courts, labour commissioners, etc.). More broadly, market 
interventions that address information asymmetries between workers and employers and promote reputational mechanisms to punish opportunistic agents might reduce contract enforcement problems. Such interventions already exist in developed economies. Singh (2002) discusses the role of a government operated labour office in Germany, called 'arbeitsamt', which performs the role of liaison between the daily wage labourers and the potential employers each of whom gather at the office every morning.

State intervention in these markets is especially important because workers themselves are unable to form trade unions, although a significant proportion of them acknowledged that the presence of a union would have reduced reneging (about one-third of those who've experienced this problem). In addition to the time and costs involved in forming a union, high regional fractionalization across nakas also implies that collective action to organise into a union might be difficult. However, given that more than 95 percent of the sample does not have political voice (in the form of a vote) in Navi Mumbai, the prospects for state intervention appear bleak. It is hoped that advocacy among the workers, either by the government or by an NGO, about the effectiveness of certain mechanisms in reducing contract breach (such as maintaining a record of work done) would lead to adoption of measures that deter employers' opportunism. 


\section{REFERENCES:}

Alesina, A. Baquir, R. \& Easterly, W. (1999), "Public Goods and Ethnic Divisions", Quarterly Journal of Economics, 114 (4), pp. 1243-1284.

Dixit, A. (2003), "Trade Expansion and Contract Enforcement," Journal of Political Economy, 111(6), pp. 1293-1317.

Dixit, A. (2004), Lawlessness and Economics: Alternative Modes of Governance Gorman Lectures in Economics. Princeton, NJ: Princeton University Press.

Fafchamps, M. (1996), “The Enforcement of Commercial Contracts in Ghana," World Development, 24 (3), 427-448.

Fafchamps, M. (2004), Market Institutions in Sub-Saharan Africa - Theory and Evidence London: MIT Press.

Fan, J. \& Gijbels, I. (1996) Local Polynomial Modelling and its Applications: Monographs on Statistics and Applied Probability 66 (Vol. 66). CRC Press.

Gambetta, D. (1993), The Sicilian Mafia: the business of private protection Harvard University Press.

Greif, A. (1993), "Contract enforceability and economic institutions in early trade: the Maghribi traders' coalition," American Economic Review, 83, pp. 525-548.

Jain, T. \& Sood, A. (2012), "How does relationship-based governance accommodate new entrants? Evidence from the cycle rickshaw rental market”, MPRA Paper No. 37424.

Kalton, G. (2001), "Practical methods for sampling rare and mobile populations," Proceedings of the Annual Meeting of the American Statistical Association, pp. 5-9.

McMillan, J. \& Woodruff, C. (1999), "Interfirm relationships and informal credit in Vietnam," Quarterly Journal of Economics, 114(4), pp. 1285-1320.

Mehrotra, S. Gandhi, A. Saha, P \& Sahoo B.K. (2012), "Joblessness and Informalization: Challenges to Inclusive Growth in India," IAMR Occasional Paper No. 9/2012. New 
Delhi: Institute for Applied Manpower Research, Planning Commission, Government of India.

Milgrom, P.R. North, D.C. \& Weingast, B.R. (1990), "The role of institutions in the revival of trade: the law merchant, private judges, and the Champagne fairs," Economics and Politics, 2, pp.1-23.

Mukherjee, P. B. Paul, G D. \& Pathan, J. I. (2009), "Migrant Workers in Informal Sector: A Probe into Working Conditions," The Adecco-TISS Labour Market Research Initiative (ALTMRI) Discussion Paper Series. Discussion Paper No. 9. Available at: https://sites.google.com/site/atlmritiss/program [Accessed on 21 November, 2014].

Ostrom, E. (1990), Governing the commons: The evolution of institutions for collective action. Cambridge University Press.

Platteau, J-P. (1994a), "Behind the market stage where real societies exist-part I: The role of public and private order institutions," The Journal of Development Studies, 30 (3), pp. 533-577.

Platteau, J-P (1994b), "Behind the market stage where real societies exist-part II: The role of moral norms," The Journal of Development Studies, 30 (4), pp. 753-817.

Reserve Bank of India (2012), "Handbook of Statistics on the Indian Economy 2011-12," Mumbai: Reserve Bank of India.

Singh, C.S.K. (2002), "Daily Labour Market in Delhi: Structure and Behaviour," Economic and Political Weekly, 37 (9), pp. 884-889.

Times of India (2008), “Maha Exodus: 10,000 north Indians flee in fear,” February 14, 2008. Available at: http://timesofindia.indiatimes.com/india/Maha-exodus-10000-northIndians-flee-in-fear/articleshow/2780795.cms. [Accessed on 21 November, 2014].

Williamson, O.E. (1985), The Economic Institutions of Capitalism New York: Free Press. 


\section{TABLES}

Table 1: Summary Statistics at the Naka Level

\begin{tabular}{|c|c|c|c|c|c|c|c|}
\hline Naka & $\begin{array}{l}\text { Sample } \\
\text { Size }\end{array}$ & $\begin{array}{l}\text { Mean (Median) } \\
\text { years of } \\
\text { experience at the } \\
\text { naka }\end{array}$ & $\begin{array}{l}\text { Linguistic } \\
\text { Fractionalization* }\end{array}$ & $\begin{array}{l}\text { Caste } \\
\text { Fractionalization* }\end{array}$ & $\begin{array}{l}\text { Share of } \\
\text { Marathi } \\
\text { Speaking } \\
\text { Workers** }\end{array}$ & $\begin{array}{l}\text { Mean (Median) } \\
\text { no. of working } \\
\text { days in a month }\end{array}$ & $\begin{array}{l}\text { Percentage of } \\
\text { labourers } \\
\text { experiencing breach } \\
\text { of contract }\end{array}$ \\
\hline Vashi & 23 & $9(8)$ & 0.465 & 0.699 & 69.56 & $13(15)$ & 39.13 \\
\hline Sanpada & 50 & $9(10)$ & 0.620 & 0.767 & 54.00 & $14(15)$ & 38.00 \\
\hline Nerul & 67 & $9(7)$ & 0.435 & 0.712 & 68.65 & $14(15)$ & 31.34 \\
\hline Belapur & 32 & $12(12)$ & 0.655 & 0.697 & 46.87 & $11(10)$ & 34.38 \\
\hline Kharghar & 123 & $6(6)$ & 0.727 & 0.761 & 36.58 & $14(15)$ & 55.28 \\
\hline Sukapur & 65 & $9(10)$ & 0.505 & 0.731 & 66.15 & $14(15)$ & 20.00 \\
\hline Kohinoor & 39 & $8(6)$ & 0.302 & 0.654 & 79.48 & $14(13)$ & 33.33 \\
\hline
\end{tabular}

Note: * See page 12 for the definition as well as the interpretation of the fractionalization index.

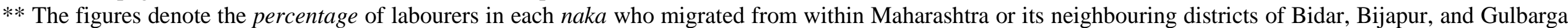
in Karnataka. 
Table 2: Daily Wages by type of Occupation

\begin{tabular}{|l|l|l|l|}
\hline Occupation & No. of workers & $\begin{array}{l}\text { Mean Wage } \\
(\text { Rs })\end{array}$ & $\begin{array}{l}\text { Median Wage } \\
(\text { Rs })\end{array}$ \\
\hline & & & \\
\hline Construction Labour - Low Wages & 105 & 269 & 300 \\
\hline Construction Labour - Medium Wages & 118 & 366 & 350 \\
\hline Construction Labour - High Wages & 54 & 575 & 575 \\
\hline Painter & 56 & 403 & 400 \\
\hline Others & 66 & 376 & 350 \\
\hline & & & \\
\hline Total & 399 & 376 & 350 \\
\hline
\end{tabular}

Note: Construction workers are classified into the three categories in the following way: Low wage workers are defined as those earning a daily wage of Rs. 300 or less; Medium-wage workers are defined as those earning a daily wage of greater than Rs. 300 but less than Rs. 500; High-wage workers are defined as those earning a daily wage of Rs. 500 and above.

Table 3: Incidence of Reneging on Wage Payments

\begin{tabular}{|l|l|l|}
\hline $\begin{array}{l}\text { Experienced Reneging on } \\
\text { wages }\end{array}$ & No. of workers & Percent \\
\hline Yes & 154 & 38.60 \\
\hline No & 245 & 61.40 \\
\hline Total Among & \multicolumn{1}{|c|}{399} & $\mathbf{1 0 0}$ \\
\hline \multicolumn{2}{|c|}{ Ahos whose payments have been reneged } \\
\hline No. of times & No. of workers & Percent \\
\hline Once & 37 & 24.03 \\
\hline Two-Three times & 56 & 36.36 \\
\hline Four-Five times & 17 & 11.04 \\
\hline More than Five times & 43 & 27.92 \\
\hline No Response & 1 & 0.65 \\
\hline Total & $\mathbf{1 5 4}$ & $\mathbf{1 0 0}$ \\
\hline
\end{tabular}

Table 4: Nature of Reneging

\begin{tabular}{|l|l|l|}
\hline Nature of Reneging & No. of workers & Percent \\
\hline Less Payment & 37 & 24.03 \\
\hline Denial of Payment & 115 & 74.68 \\
\hline Others & 2 & 1.3 \\
\hline Total & $\mathbf{1 5 4}$ & $\mathbf{1 0 0}$ \\
\hline
\end{tabular}


Table 5: Loss from Reneging

\begin{tabular}{|l|l|l|}
\hline Loss of wage income from reneging (Approx.) & No. of workers & Percent \\
\hline Less than Rs. 1,000 & 21 & 13.64 \\
\hline Rs. 2,000 - Rs. 3,000 & 22 & 14.29 \\
\hline Rs. 3,000 - Rs. 5,000 & 20 & 12.99 \\
\hline Rs. 5,000 - Rs. 10,000 & 29 & 18.83 \\
\hline More than Rs. 10,000 & 59 & 38.31 \\
\hline No Response & 3 & 1.95 \\
\hline Total & $\mathbf{1 5 4}$ & $\mathbf{1 0 0}$ \\
\hline
\end{tabular}

Table 6: Labourers' Redressal Mechanism

\begin{tabular}{|l|l|l|}
\hline Labourers' Reaction to reneging & No. of workers & Percent \\
\hline Did Nothing & 144 & 93.51 \\
\hline Complained to Police & 3 & 1.95 \\
\hline Complained to Labour Commissioner & 1 & 0.65 \\
\hline Others & 1 & 0.65 \\
\hline No Response & 5 & 3.25 \\
\hline Total & $\mathbf{1 5 4}$ & $\mathbf{1 0 0}$ \\
\hline
\end{tabular}

Table 7: Incidence of Reneging - Caste wise - Marathis and Non-Marathis:

\begin{tabular}{|l|l|l|l|l|}
\hline Caste & $\begin{array}{l}\text { Sample Size } \\
\text { (Marathis*) }\end{array}$ & $\begin{array}{l}\text { Sample Size } \\
\text { (Non- } \\
\text { Marathis) }\end{array}$ & $\begin{array}{l}\text { Incidence of } \\
\text { Reneging - } \\
\text { Marathis* } \\
\text { (Percent) }\end{array}$ & $\begin{array}{l}\text { Incidence of } \\
\text { Reneging - } \\
\text { Non-Marathis } \\
\text { (Percent) }\end{array}$ \\
\hline Scheduled Castes & 116 & 33 & 35.34 & 57.58 \\
\hline Scheduled Tribes & 51 & 43 & 31.37 & 32.56 \\
\hline Other Backward Castes & 29 & 50 & 48.28 & 44.00 \\
\hline Others & 27 & 50 & 22.22 & 44.00 \\
\hline Total & $\mathbf{2 2 3}$ & $\mathbf{1 7 6}$ & $\mathbf{3 3 . 7 7}$ & $\mathbf{4 3 . 7 5}$ \\
\hline
\end{tabular}

Note: * Marathi migrants include those who migrated from within Maharashtra or its neighbouring districts of Bidar, Bijapur, and Gulbarga. 
Table 8: Incidence of Reneging - Social Networks

\begin{tabular}{|l|c|c|}
\hline $\begin{array}{l}\text { Source of information about the naka and distance of native } \\
\text { district from Mumbai }\end{array}$ & $\begin{array}{c}\text { No of } \\
\text { workers }\end{array}$ & $\begin{array}{c}\text { Incidence } \\
\text { of } \\
\text { Reneging } \\
\text { (Percent) }\end{array}$ \\
\hline $\begin{array}{l}\text { Migrated from less than } 550 \mathrm{~km} \text { and came through friends \& } \\
\text { relatives }\end{array}$ & 140 & 34 \\
\hline Migrated from less than $550 \mathrm{~km}$ and came through others* & 88 & 33 \\
\hline $\begin{array}{l}\text { Migrated from greater than } 550 \mathrm{~km} \text { and came through friends \& } \\
\text { relatives }\end{array}$ & 109 & 41 \\
\hline Migrated from greater than $550 \mathrm{~km}$ and came through others* & 62 & 52 \\
\hline
\end{tabular}

Note: * The category of 'others' includes migrants who learnt about these markets on their own (30 percent of the sample), or through a contractor ( 2 percent of the sample). 
Table 9: Odds ratio of Logistic Regression Predicting Chances of Wage Payments Being Reneged (Capturing effect of social network among long-distance migrants):

\begin{tabular}{|c|c|c|c|c|}
\hline & Model 1 & Model 2 & Model 3 & Model 4 \\
\hline $\begin{array}{l}\text { Market characteristic considered for each } \\
\text { model: }\end{array}$ & $\begin{array}{l}\text { Market } \\
\text { Size }\end{array}$ & $\begin{array}{c}\text { Linguistic } \\
\text { Fractionalization } \\
\text { at the Naka }\end{array}$ & $\begin{array}{c}\text { Share of } \\
\text { Marathi } \\
\text { Speaking } \\
\text { Workers } \\
\text { at the } \\
\text { Naka }\end{array}$ & $\begin{array}{c}\text { Caste } \\
\text { Fractionalization } \\
\text { at the Naka }\end{array}$ \\
\hline VARIABLES & & & & \\
\hline
\end{tabular}

Education: Above Matriculation

(Reference group: Below Matriculation)

$\begin{array}{cccc}0.912 & 0.947 & 0.926 & 0.981 \\ (0.334) & (0.348) & (0.341) & (0.360)\end{array}$

Religion: (Reference group: Hindus) Islam

$\begin{array}{cccc}1.058 & 0.974 & 0.993 & 0.981 \\ (0.443) & (0.386) & (0.394) & (0.399) \\ 1.816 & 1.572 & 1.523 & 1.771 \\ (0.791) & (0.696) & (0.676) & (0.773) \\ 0.384 & 0.310 & 0.311 & 0.340 \\ (0.447) & (0.372) & (0.382) & (0.385)\end{array}$

Caste: (Reference group: OBCs) SC

$\begin{array}{cccc}0.773 & 0.850 & 0.832 & 0.845 \\ (0.269) & (0.294) & (0.290) & (0.289) \\ 0.524^{*} & 0.586 & 0.572 & 0.576 \\ (0.198) & (0.213) & (0.211) & (0.210) \\ 0.542 * & 0.541 * & 0.521 * & 0.581 \\ (0.199) & (0.201) & (0.194) & (0.213)\end{array}$

Record of work done: (Reference group: those who do not have work record)

Work Type: (Reference group: Construction sector medium wage workers) Construction-Low

Wages

Construction-High Wages

Painter

Others

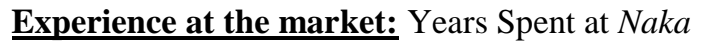
Square of Years Spent at Naka
1.297

(0.393)

1.473

(0.566)

$2.097 * *$

(0.771)

1.171

(0.426)

$0.910 * *$

(0.0408)

$1.004 * *$

(0.00166)
1.245

(0.378)

1.571

(0.590)

$2.091 * *$

(0.772)

1.334

(0.483)

$0.901 * *$

$(0.0405)$

$1.004 * *$

(0.00164)
1.247

(0.380)

1.590

(0.600)

2.047*

(0.759)

1.289

(0.467)

$0.903 * *$

(0.0408)

$1.004 * *$

(0.00166)
1.244

(0.373)

1.486

(0.559)

2.168**

(0.795)

1.325

(0.481)

$0.903 * *$

(0.0402)

$1.004 * *$

(0.00163) 
Interaction dummy for information about the market and distance of workers' origin district from Mumbai: (Reference group: Workers who came from $<550 \mathrm{Kms}$ )

Came to the naka through Friends \& Relatives from $>550 \mathrm{Kms}$

1.520

(0.614)

1.550

(0.628)

1.474

1.720

(0.600)

$(0.691)$

Came to the naka by themselves or through contractor from $>550 \mathrm{Kms}$

$$
2.867 * *
$$

$$
2.678 * *
$$

Distance of origin district from Mumbai

$$
\begin{gathered}
1.000 \\
(0.000439)
\end{gathered}
$$

1.000
$(0.000442)$

1.017

$(0.0272)$

1.021
$(0.0278)$

Size (of the market)

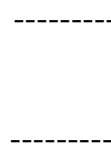

$1.463 * * *$

(0.205)

Share of Marathi Workers at the Naka

Caste Fractionalisation at the Naka

$$
\text { Constant }
$$

Observations

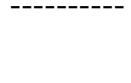

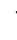

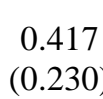

(0.230)

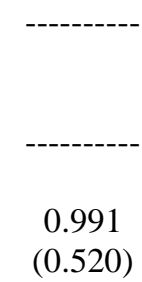

$0.0565 * * *$
$(0.0503)$

1.000
$(0.000440)$

1.000

$(0.000447)$

1.020
$(0.0283)$

1.023

(0.0264)

391

391

Note: Robust standard errors in parentheses $* * * \mathrm{p}<0.01, * * \mathrm{p}<0.05, * \mathrm{p}<0.1$.

Coefficients are to be interpreted as odds-ratios. 
Table 10: Odds ratio of Logistic Regression Predicting Chances of Wage Payments Being Reneged (Interacting caste and Marathi status):

$\begin{array}{ccccc} & \text { Model 5 } & \text { Model 6 } & \text { Model } 7 & \text { Model 8 } \\ \begin{array}{c}\text { Market characteristic considered for each } \\ \text { model: }\end{array} & \text { Market } & \text { Linguistic } & \text { Share of } & \text { Caste } \\ & \text { Size } & \text { Fractionalization } & \text { Marathi Fractionalization } \\ & & \text { at the Naka } & \begin{array}{c}\text { Speaking } \\ \text { at the Naka }\end{array} \\ & & & \text { Workers } & \text { at the } \\ \text { VARIABLES } & & \text { Naka } & \end{array}$

Education: Above Matriculation (Reference group: Below Matriculation)

$\begin{array}{cccc}0.943 & 0.972 & 0.953 & 1.008 \\ (0.351) & (0.361) & (0.356) & (0.371) \\ & & & \\ 1.079 & 0.985 & 1.009 & 0.987 \\ (0.430) & (0.372) & (0.383) & (0.383) \\ 2.036 & 1.753 & 1.708 & 1.979 \\ (0.944) & (0.820) & (0.805) & (0.908) \\ 0.297 & 0.244 & 0.240 & 0.280 \\ (0.392) & (0.326) & (0.326) & (0.356) \\ & & & \\ 0.447 * * & 0.450 * * & 0.430 * * & 0.490 * * \\ (0.162) & (0.165) & (0.159) & (0.176) \\ 1.518 & 1.730 & 1.729 & 1.658 \\ (0.676) & (0.771) & (0.778) & (0.727) \\ 0.381^{* *} & 0.424 * * & 0.413 * * & 0.418 * * \\ (0.156) & (0.173) & (0.170) & (0.168) \\ 0.772 & 0.853 & 0.824 & 0.861 \\ (0.321) & (0.344) & (0.339) & (0.340) \\ 0.216^{* * *} & 0.253 * * & 0.252^{* *} & 0.234 * * \\ (0.127) & (0.147) & (0.146) & (0.138)\end{array}$

Record of work done: (Reference group: those who do not have work record)

$0.401 * *$

$(0.155)$

$0.432 * *$

(0.166)

$0.394 * *$

$(0.154)$

$0.502 *$

$(0.188)$
Work Type: (Reference group: Construction sector medium wage workers) Construction-Low Wages

Construction-High Wages

$$
\begin{aligned}
& \text { Painter } \\
& \text { Others }
\end{aligned}
$$

Experience at the market: Years Spent at Naka

Square of Years Spent at Naka

\section{Dummy for information about the market:}

(Reference group: those who did not come to

$$
\text { know through friends or relatives) }
$$

$$
0.724
$$

(0.170)

1.254
$(0.386)$
1.509
$(0.559)$
$2.162 * *$
$(0.809)$
1.376
$(0.508)$

$0.897 * *$

$(0.0403)$

$1.004 * *$

(0.00164)
1.247

$(0.386)$

1.521

(0.566)

$2.133 * *$

(0.801)

1.331

(0.492)

1.270

(0.385)

1.425

(0.527)

$2.215 * *$

(0.821)

1.345

(0.492)

$0.899 * *$

(0.0408)

$1.004 * *$

$0.900 * *$

(0.0400)

$1.004 * *$

(0.00166) 
Distance of origin district from Mumbai

Previous Experience of Migration

Size (of the market)

Linguistic Fractionalisation at the Naka

Share of Marathi Workers at the Naka

Caste Fractionalisation at the Naka

Constant
1.000

$(0.000378)$

1.012

$(0.0300)$

$1.012 * * *$

$(0.00363)$
1.000

$(0.000387)$

$(0.000390)$

\begin{tabular}{|c|c|c|c|c|}
\hline Size (of the market) & $\begin{array}{l}1.012 * * * \\
(0.00363)\end{array}$ & --------- & --------- & -------- \\
\hline Linguistic Fractionalisation at the $N a k a$ & --------- & $\begin{array}{l}1.516 * * * \\
(0.210)\end{array}$ & --------- & --------- \\
\hline Share of Marathi Workers at the Naka & --------- & --------- & $\begin{array}{c}0.0431 * * * \\
(0.0379)\end{array}$ & --------- \\
\hline Caste Fractionalisation at the Naka & --------- & --------- & --------- & $\begin{array}{c}1.284 * \\
(0.168)\end{array}$ \\
\hline Constant & $\begin{array}{c}0.819 \\
(0.499)\end{array}$ & $\begin{array}{c}1.976 \\
(1.167)\end{array}$ & $\begin{array}{c}12.30 * * * \\
(10.15)\end{array}$ & $\begin{array}{c}1.717 \\
(0.999)\end{array}$ \\
\hline
\end{tabular}

Observations

391

391

391

391

Note: Robust standard errors in parentheses $* * * \mathrm{p}<0.01, * * \mathrm{p}<0.05, * \mathrm{p}<0.1$. Coefficients are to be interpreted as odds-ratios. 
Figure 1: Incidence of Reneging With Respect to Workers' Experience at the Naka

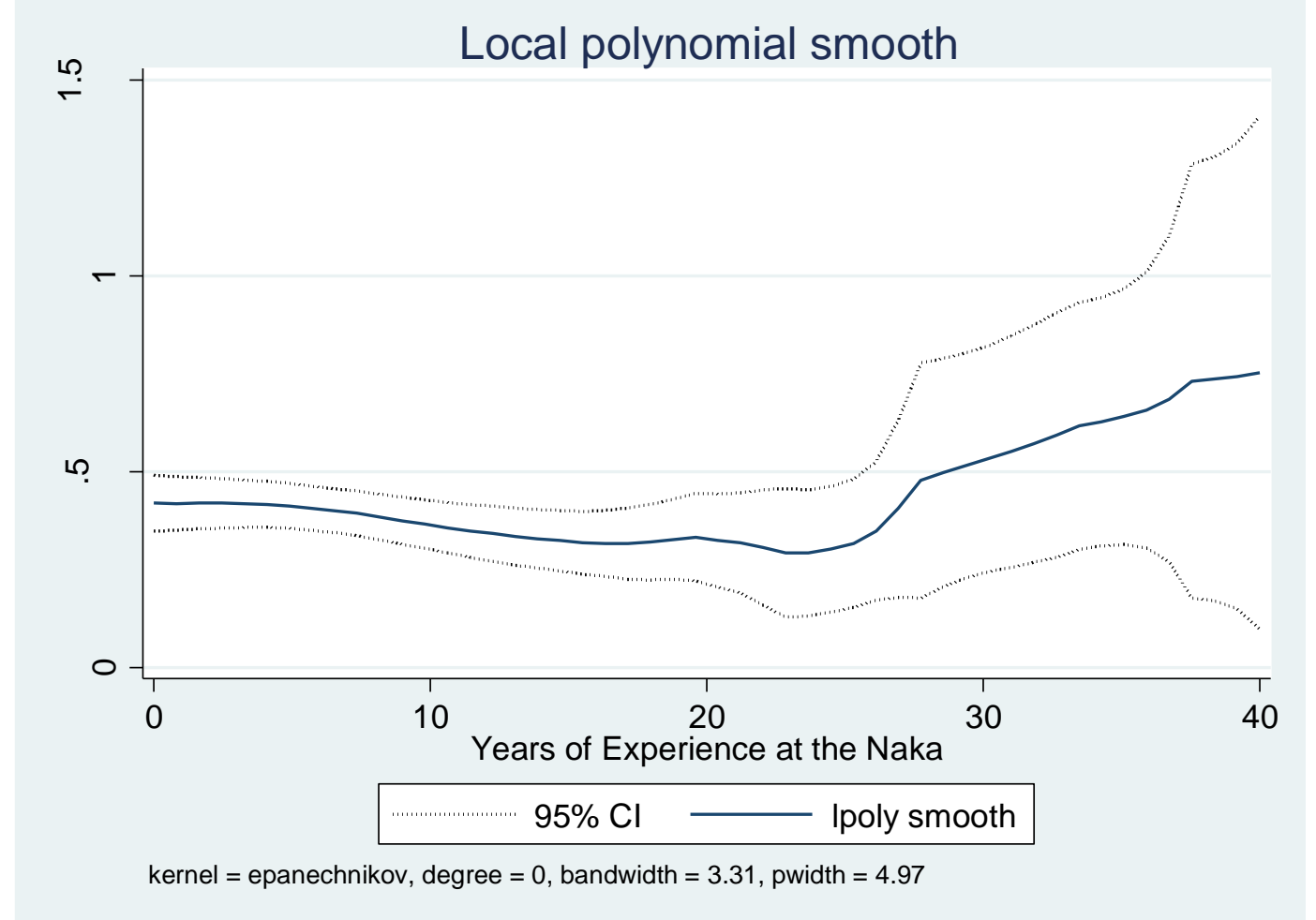

Note: In the above graph, we capture the impact of experience of working at the nakas on the incidence of wage reneging. 